\title{
LETTER
}

Acute myeloid leukemia

\section{Autologous CD33-CAR-T cells for treatment of relapsed/refractory acute myelogenous leukemia}

\author{
Francesco Paolo Tambaro ${ }^{1,2} \cdot$ Harjeet Singh $\mathbb{D}^{1} \cdot$ Emily Jones $^{3} \cdot$ Michael Rytting $^{1} \cdot$ Kris M. Mahadeo $\mathbb{D}^{1}$. \\ Philip Thompson $\mathbb{1}^{3} \cdot$ Naval Daver ${ }^{3}$. Courtney DiNardo $\mathbb{D}^{3} \cdot$ Tapan Kadia $\mathbb{D}^{3} \cdot$ Guillermo Garcia-Manero $\mathbb{D}^{3}$. \\ Tim Chan ${ }^{4} \cdot$ Rutul R. Shah ${ }^{4} \cdot$ William G. Wierda $\mathbb{D}^{3}$
}

Received: 8 October 2020 / Revised: 14 February 2021 / Accepted: 12 March 2021 / Published online: 8 April 2021

(c) The Author(s), under exclusive licence to Springer Nature Limited 2021. This article is published with open access

\section{To the Editor:}

Acute myelogenous leukemia (AML) is a potentially curable disease; $70 \%$ of newly diagnosed patients achieve complete remission with first-line therapy, but prognosis worsens for relapsed disease in both pediatric and adult patients. A recent study examined long-term overall survival (OS) in relapsed patients with AML enrolled to nine successive ECOG-ACRIN trials for newly diagnosed AML between 1984 and 2008. Importantly, a median OS of 6 months from relapse and 10\% 5-year OS were reported [1]. Recently, encouraging results were reported for targeted agents against molecular markers associated to the poor prognosis in relapsed disease given as monotherapy or combined with chemotherapy, including FLT3- [2], IDH1[3] and IDH2-inhibitors [4].

Remarkable results were achieved with CAR-modified $\mathrm{T}$ cells targeting CD19 in relapsed/refractory patients with diffuse large B cell lymphoma (DLBCL) [5] and pediatric B cell acute lymphoblastic leukemia (ALL) [6] (50-90\%

Supplementary information The online version contains supplementary material available at https://doi.org/10.1038/s41375021-01232-2.

$\triangle$ William G. Wierda

wwierda@mdanderson.org

1 Department of Pediatrics, The University of Texas MD Anderson Cancer Center, Houston, TX, USA

2 Unità Operativa di Trapianto di Midollo Osseo e Servizio Trasfusionale; Azienda Ospedaliera di Rilievo Nazionale Santobono-Pausilipon, Napoli, Italy

3 Department of Leukemia, The University of Texas MD Anderson Cancer Center, Houston, TX, USA

4 Precigen, Inc.20358 Seneca Meadows Parkway, Germantown, MD, USA
CR), which inspired development of CAR-T cellular therapy for other indications, such as AML. Identifying a myeloid target for CAR-T cellular therapy has proven challenging, since surface antigens are shared by malignant myelogenous cells and normal hematopoietic stem cells, potentially resulting in prolonged myelotoxicity when tested in clinical trials. CD33, a member of the sialic acid-binding Ig-like lectin family, is expressed on subpopulations of leukemia cells, including leukemic stem cells, in almost $90 \%$ of AML cases as well as on some normal myeloid precursors [7].

We initiated a single-center, single-arm, Phase I clinical trial (NCT03126864) to investigate the feasibility and safety of autologous $\mathrm{T}$ cells, modified to express a CD33-targeted CAR with 4-1BB and CD3ל endo-domains and coexpressed with truncated human epidermal growth factor receptor (HER1t) [8], in patients with relapsed/refractory AML. The goals of this Phase I clinical trial were to assess the feasibility and safety of adoptive transfer of the autologous CD33-CAR-T cells identify the recommended Phase II dose. Details of the clinical trial, including product release criteria (Table S1), can be found in the Supplementary Material.

Ten adults with relapsed/refractory AML were enrolled; 7 were male; median age was 30 (range 18-73) years (Table 1). Patients had received a median of 5 (range 3-8) prior treatment regimens; 3 underwent prior allogeneic stem cell transplant. The median percent bone marrow blasts at screening, WBC, the percent peripheral blood blasts and the lymphocyte count at apheresis were $55 \%(10-88), 1.6 / \mu \mathrm{l}$

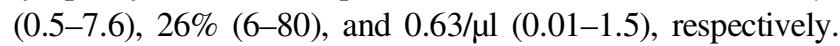
Apheresis was collected for 8 patients; 4 had CD33-CAR-T cells produced which met release pre-specified release criteria for infusion; 4 had CD33-CAR-T cell product that failed to meet at least one pre-specified release criteria; and 2 patients had rapidly progressive AML and could not undergo apheresis (Table 2). Three patients received CD33-CAR-T cells at 
Table 1 Patient characteristics and treatment.

\begin{tabular}{|c|c|c|c|c|c|c|c|c|c|c|}
\hline Patient number & 01 & 02 & 03 & 04 & 06 & $(05) 07 *$ & 08 & 09 & 10 & 11 \\
\hline Sex & M & M & M & M & M & M & M & $\mathrm{F}$ & $\mathrm{F}$ & $\mathrm{F}$ \\
\hline Age & 36 & 73 & 38 & 18 & 18 & 18 & 52 & 24 & 56 & 19 \\
\hline Number Prior therapies & 6 & 7 & 5 & 5 & 5 & 7 & 8 & 5 & 3 & 5 \\
\hline$\%$ BM Blasts at screening & 10 & 18 & 50 & 60 & 47 & 86 & 27 & 66 & 60 & 85 \\
\hline Number $\mathrm{WBC} / \mu \mathrm{l}$ at apheresis & 0.8 & 5.4 & 1.7 & 0.9 & 0.5 & 7.6 & 5.5 & na & na & 1.5 \\
\hline Number lymphocytes/mL at apheresis (\%) & $0.16(20)$ & $1.5(28)$ & $0.48(28)$ & $0.6(67)$ & $0.01(2)$ & $0.76(10)$ & $0.66(12)$ & na & na & $0.92(61)$ \\
\hline$\%$ PB Blasts at apheresis & 6 & 21 & 63 & 20 & 80 & 74 & 8 & na & na & 31 \\
\hline Apheresis & $\mathrm{y}$ & $\mathrm{y}$ & $\mathrm{y}$ & $\mathrm{y}$ & $\mathrm{y}$ & $\mathrm{y}$ & $\mathrm{y}$ & $\mathrm{n}$ & $\mathrm{n}$ & $\mathrm{y}$ \\
\hline$\% \mathrm{~T}$ cells in apheresis product & 14.6 & 33.5 & 23.2 & 45.7 & 46.4 & 4 & 7.1 & na & na & 64.6 \\
\hline$\% \mathrm{CD} 3^{+}$blasts in apheresis product & 54.7 & 24.4 & 60.9 & 45.4 & 34.2 & 94.6 & ND & na & na & 22.5 \\
\hline CD33-CAR-T cells product released (y/n) & $\mathrm{n}$ & $\mathrm{y}$ & $\mathrm{y}$ & $\mathrm{n}^{\#}$ & $\mathrm{y}$ & $\mathrm{n}$ & $\mathrm{n}$ & na & na & $\mathrm{y}$ \\
\hline CD33-CAR-T cell infusion $(y / n)$ & $\mathrm{n}$ & $\mathrm{n}$ & $\mathrm{y}$ & $\mathrm{n}$ & $\mathrm{y}$ & $\mathrm{n}$ & $\mathrm{n}$ & na & na & $\mathrm{y}$ \\
\hline Apheresis to CD33-CAR-T infusion (days) & na & na & 94 & na & 36 & na & na & na & na & 49 \\
\hline Dose $\left(\times 10^{6} / \mathrm{kg}\right)$ & na & na & 0.3 & na & 0.3 & na & na & na & na & 0.3 \\
\hline
\end{tabular}

y, yes; n, no; na, not applicable; ND, not determined; \#, number.

${ }^{*}$ Pts 5 and 7 were same patient.

\# For Pt 4, sufficient CD33-CAR-T cells were manufactured but \%CD3 +-CAR + was below release specification and product lot was successfully released per agreement with the FDA.

the first dose level $\left(0.3 \times 10^{6} \mathrm{CD} 33-\mathrm{CAR}-\mathrm{T} / \mathrm{kg}\right)$ and 1 patient died before receiving their cells. The time from apheresis to CD33-CAR-T cell infusion is shown (Table 1).

Table 2 summarizes blood cell and cytokine levels preand blood cell and cytokine levels, toxicities and outcomes following infusion of CD33-CAR-T cells for all 3 treated patients. No dose-limiting toxicities (DLTs) were observed (Table 2) at dose level 1 during the 28-day DLT assessment period. Two patients experienced cytokine release syndrome (CRS) and 1 patient developed immune effector cell-associated neurotoxicity syndrome (ICANS). Adverse events possibly related to CD33-CAR-T cells included a grade 3 tumor lysis syndrome-acute kidney injury, grade 2 mucositis, grade 1 tachycardia for 1 patient; and a second patient experienced grade 2 intermittent orthostatic hypotension, grade 2 increased bilirubin and grade 3 increased ALT and AST. One patient experienced no toxicity. Adverse Events unrelated to the treatment were grade 3 respiratory distress syndrome in one patient and grade 3 febrile neutropenia and grade 4 sepsis and septic shock in another patient. All three patients who received CD33-CAR-T cells have died, due to disease progression.

All 3 patients had leukopenia on the day of CD33CAR-T cell infusion; 2 had circulating blasts. Two methods were used to detect circulating CAR-T cells: flow cytometry with fluorescently labeled cetuximab and digital droplet polymerase chain reaction (ddPCR) for HER1t. CD33-CAR-T cells were detected by both methods. Patient 03 and 11 had CRS and had associated increase in blood IL-6 level. Despite the activity seen, none of the patients met criteria for response to treatment. There was in vivo evidence of CD33-CAR-T cells at this lowest dose level, which was associated with increase in inflammatory cytokine levels (IL6, IFN $\gamma, \mathrm{TNF} \alpha$ ) concurrent with ICANS and CRS, and for only those who manifested these symptoms (Table 2). No pediatric patients were enrolled due to closure of the trial upon clearing the first dose level with no DLT.

Due to challenges posed by the aggressive nature of relapsed/refractory AML and need for expeditious autologous product generation, logistic and enrollment challenges, the trial was closed to patient entry after patient 11 was enrolled and treated. The sponsors have transitioned to a platform that facilitates more rapid production and in vivo expansion with a product referred to as PRGN-3006 (NCT03927261) [9, 10].

We could detect CD33-CAR-T cells in blood samples from patients following infusion with associated symptoms and increased cytokine levels. Despite this biologic activity, we did not see anti-leukemia responses, although patients received only one dose of CD33-CAR-T cells, and this was the lowest dose level. A single case report of a patient with relapsed AML treated with CD33-CAR-T cells suggested therapeutic activity with associated symptoms and increase in inflammatory cytokine levels (NCT01864902) [11]. No further follow up has been provided for this trial. Our trial illustrated challenges associated with CAR-T therapy for 


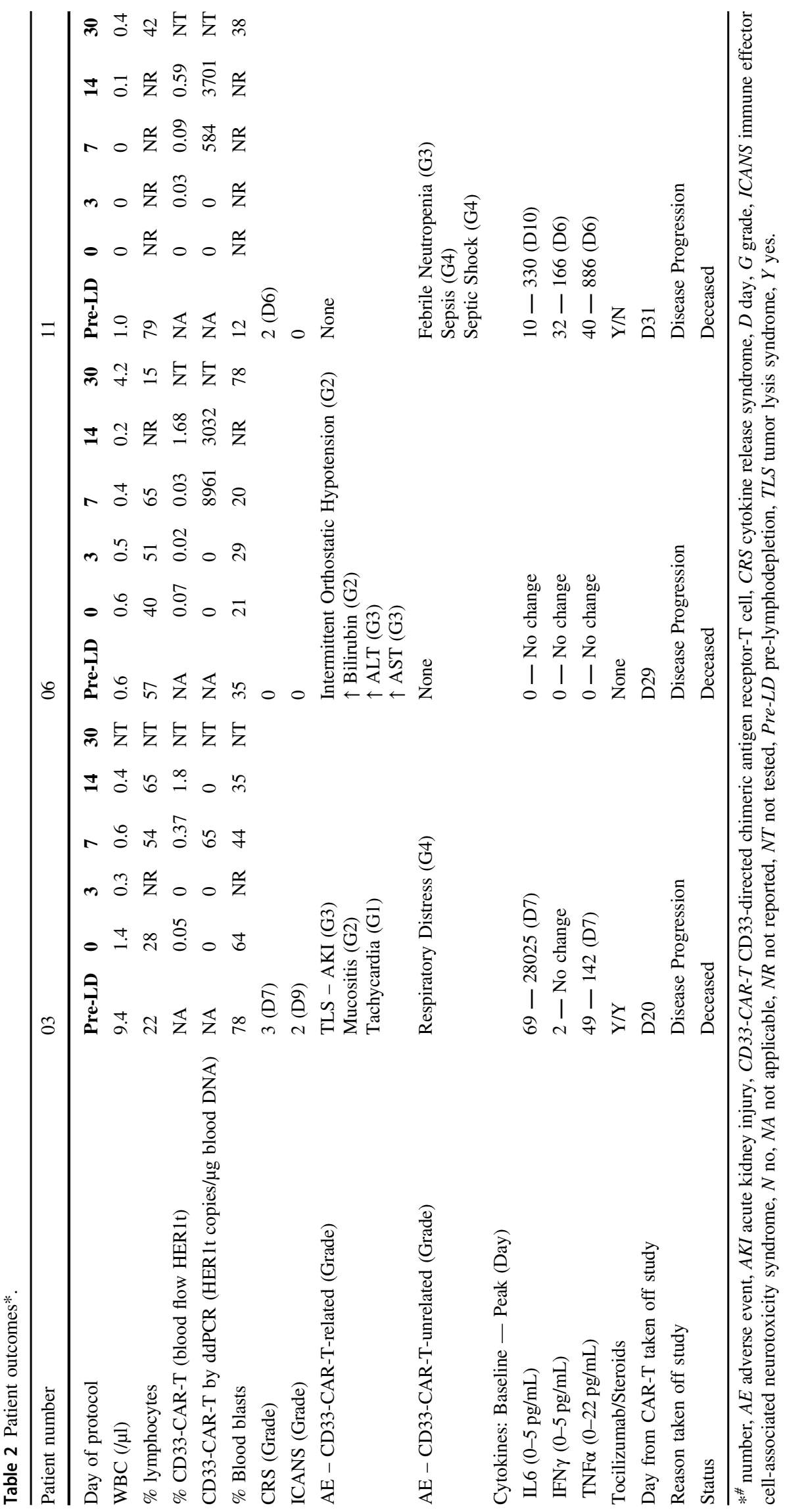


patients with relapsed/refractory AML which relate to manufacturing using viral vectors, rapid disease progression and risk for infection, and coordination of administration of this therapeutic modality.

Most patients with relapsed/refractory AML have lymphopenia and many have increased number of circulating blood blasts, which complicate and increase difficulty of producing autologous CAR-T cells. In this clinical trial, there were 10 patients enrolled and the cell product meeting all prespecified release criteria was successfully made for 4 of these patients. Two enrolled patients were unable to undergo apheresis. Challenges included rapid disease progression and high blood blast count, lymphopenia and difficulty with acquiring adequate number of starting $\mathrm{T}$ cells in the apheresis step, difficulty of manufacturing using lentiviral vector, and disease progression or infection during lengthy production time, all of which contributed to inability to receiving product for some patients enrolled in this trial. Therefore, for patients with AML, there is need to develop a strategy which eliminates or markedly shortens manufacturing time to address the shortcomings of lentiviral transduction.

Relapsed/refractory AML is typically an aggressive disease with a rapid, unrelenting tempo of progression. Due to depletion of myeloid cells by the disease and treatments, patients are severely immunodeficient and at very high risk for infection. Considering the logistics and time of 2-4 weeks required for production and release with lentiviral and retroviral transduction, there is a significant timeat-risk for patients with respect to both progressive AML and infection. Events during this period represent a significant risk to receiving lymphodepletion and CAR-T cell product. "Bridging" chemotherapy has been used, but has associated toxicity and is usually myelosuppressive and immunosuppressive.

An ideal CAR-T cell target should to be easily accessible, expressed on the surface of all cancer cells and not be shared by viable tissues or normal hematopoietic cells, in order to reduce the eventual toxicity and side effects. AML antigen targets are usually also expressed on normal hematopoietic cells, which may result in undesired prolonged myelosuppression. Clinical trials are ongoing to test CAR-T cells targeting antigens other than CD33 on myeloid blasts including: CD123 (NCT03766126, NCT03114670, NCT03190278, NCT04230265, NCT03631576), IL1 receptor accessory protein (IL1RAP) (NCT04169022), CLL-1 (NCT04219163), CD38 (NCT04351022), and FLT3 (NCT03904069). Despite expression on some normal myeloid progenitors, CD33 remains a reasonable and attractive therapeutic target. We observed in vivo CD33CAR-T cells and activity and symptoms consistent with this observation. There are ongoing trials with CD33-CAR-T cell strategies (NCT03971799, NCT03927261).
In conclusion, autologous CD33-CAR-T cell production via lentiviral transduction was challenging, and was feasible only in patients with higher lymphocyte count and lower blood blasts. No DLTs were noted at the first dose level and in vivo CD33-CAR-T cells were detected. CRS and ICANS occurred, and were manageable for this lowest dose cohort. Higher $\mathrm{T}$ cell count at apheresis and rapid manufacturing strategies that reduce time from apheresis to treatment will be essential in CAR-T treatments for these challenging patients with relapsed/refractory AML.

Funding This study and correlative laboratory investigations were funded by Ziopharm.

Author contributions FPT: Analyzed and summarized data, wrote manuscript, reviewed and approved manuscript. HS: Correlative laboratory studies, data collection and summary, reviewed and approved manuscript. EJ: Research nurse, coordinated patient schedules, reviewed and approved manuscript. MR: Reviewed and assisted in writing protocol, reviewed and approved manuscript. KM: Collaborator, reviewed and approved manuscript. PT: Referred patients, collaborator, reviewed and approved manuscript. ND: Referred patients, collaborator, reviewed and approved manuscript. CD: Referred patients, collaborator, reviewed and approved manuscript. TK: Referred patients, collaborator, reviewed and approved manuscript. GGM: Referred patients, collaborator, reviewed and approved manuscript. TC:Performed pre-clinical work, reviewed and approved manuscript. RRS: Performed pre-clinical work, reviewed protocol, reviewed and approved manuscript. WGW: Designed and wrote protocol, enrolled and treated patients, oversaw data collection, supervised data analysis and summary and writing of manuscript, reviewed and approved manuscript

\section{Compliance with ethical standards}

Conflict of interest FPT: No relevant conflicts of interest to report. HS: Research funding from Precigen/Intrexon. EJ: No relevant conflicts of interest to report. MR: No relevant conflicts of interest to report. KM: No relevant conflicts of interest to report. PT: No relevant conflicts of interest to report. ND: No relevant conflicts of interest to report. CD: No relevant conflicts of interest to report. TK: No relevant conflicts of interest to report. GGM: No relevant conflicts of interest to report. TC: Employee of Precigen/Intrexon. RRS: Employee of Precigen/Intrexon. WGW: No relevant conflicts of interest to report.

Publisher's note Springer Nature remains neutral with regard to jurisdictional claims in published maps and institutional affiliations.

Open Access This article is licensed under a Creative Commons Attribution 4.0 International License, which permits use, sharing, adaptation, distribution and reproduction in any medium or format, as long as you give appropriate credit to the original author(s) and the source, provide a link to the Creative Commons license, and indicate if changes were made. The images or other third party material in this article are included in the article's Creative Commons license, unless indicated otherwise in a credit line to the material. If material is not included in the article's Creative Commons license and your intended use is not permitted by statutory regulation or exceeds the permitted use, you will need to obtain permission directly from the copyright holder. To view a copy of this license, visit http://creativecommons. org/licenses/by/4.0/. 


\section{References}

1. Ganzel C, Sun Z, Cripe LD, Fernandez HF, Douer D, Rowe JM, et al. Very poor long-term survival in past and more recent studies for relapsed AML patients: The ECOG-ACRIN experience. Am J Hematol. 2018. https://doi.org/10.1002/ajh.25162.

2. Cortes JE, Tallman MS, Schiller GJ, Trone D, Gammon G, Goldberg SL, et al. Phase $2 b$ study of 2 dosing regimens of quizartinib monotherapy in FLT3-ITD-mutated, relapsed or refractory AML. Blood. 2018;132:598-607.

3. DiNardo CD. Ivosidenib in IDH1-mutated acute myeloid leukemia. N. Engl J Med. 2018;379:1186.

4. Stein EM, DiNardo CD, Pollyea DA, Fathi AT, Roboz GJ, Altman JK, et al. Enasidenib in mutant IDH2 relapsed or refractory acute myeloid leukemia. Blood. 2017;130:722-31.

5. Neelapu SS, Locke FL, Bartlett NL, Lekakis LJ, Miklos DB, Jacobson CA, et al. Axicabtagene ciloleucel CAR T-cell therapy in refractory large B-cell lymphoma. N Engl J Med. 2017;377:2531-44.

6. Maude SL, Frey N, Shaw PA, Aplenc R, Barrett DM, Bunin NJ, et al. Chimeric antigen receptor $\mathrm{T}$ cells for sustained remissions in leukemia. N Engl J Med. 2014;371:1507-17.
7. Walter RB, Appelbaum FR, Estey EH, Bernstein ID. Acute myeloid leukemia stem cells and CD33-targeted immunotherapy. Blood. 2012;119:6198-208.

8. Song D, Swartz MH, Tian L, Carvajal-Borda F, Plummer J, Shah $\mathrm{RR}$, et al. Autologous T cells modified to co-express CD33-specific chimeric antigen receptor and a kill switch for treatment of CD33+ acute myeloid leukemia. Blood. 2017; 130 (Suppl 1): Abstract 1376.

9. Chan T, Ma X, Carvajal-Borda F, Velez J, Plummer J, Shepard L, et al. Preclinical characterization of Prgn-3006 ultracar-TTM for the treatment of AML and MDS: non-viral, multigenic autologous CAR-T cells administered one day after gene transfer. Blood. 2019; 134 (Suppl 1): Abstract 2660.

10. Sallman D, Elmariah H, Sweet K, Talati C, Mishra A, Kelley L, et al. A Phase $1 / 1 \mathrm{~b}$ safety study of Prgn-3006 Ultracar-T ${ }^{\mathrm{TM}}$ in patients with relapsed or refractory CD33-positive acute myeloid leukemia and higher risk myelodysplastic syndrome. Blood. 2020; 136(Suppl 1): (Abstract 2864).

11. Wang QS, Wang Y, Lv HY, Han QW, Fan H, Guo B, et al. Treatment of CD33-directed chimeric antigen receptor-modified $\mathrm{T}$ cells in one patient with relapsed and refractory acute myeloid leukemia. Mol Ther. 2015;23:184-91. 